\title{
Successive Steps of Knowledge and the Ancient Myth about Cassandra
}

\author{
By Vladimir Romanenko* \\ Galina Nikitina
}

The creative process requires different mental properties from its authors. The abilities of observe, compare and explain are the most important of them. In real life it is impossible to find a person who possesses all necessary behaviours. As a result, one person usually cannot fulfil all requirements of solving serious new problem. That is why several individuals with different sets of mental properties participate in each creative process. This fact was first detected by the Ancient Greeks. It was reflected in the set of myths devoted to Cassandra. Some modern explanations of this fact are discussed. We describe several examples of practical skills of authors of novelties needed at the different stages of the creative process. Three main stages of creative process were detected. Special attention was paid for understanding of specific properties of persons connected with the practical implementation of a new idea.

Keywords: Definition of the problem, Implementation of the problem solution Personal behaviours, Predictions, Stages of the creative process.

\section{Introduction}

Each living body needs to forecast the changes in its environment and explain the observed phenomena. The forecasting actions are frequently denoted as Probabilistic Prognosis (Feigenberg 2014). Animal forecasting is based only on previous experience. Unlike animals, people set more challenging goals. Over time the human behaviors, i.e. a sequence of actions, began to be tied up with the specific goals (Vygotsky 1978, 1986). The presence of a goal of actions differs humans from other animals. Therefore, we can speak about the specific human property denoted as the mind. Known methods of finding solutions to the human brain did not arise at once. These methods evolved along with the evolution of humanity. It is well known that scientific and religious explanations of the outside world were not formed immediately. There was a long period in the history of mankind which was sometimes pre-scientific. This period can also be divided into stages. During each of these stages ancient people stored in their memory recollections about real events and general ideas of various phenomena. All this data can be well

\footnotetext{
* Head of Scientific Council, North-Western Branch of Academy of Information Technologies in Education, Russia.

* General Scientific Secretary, North-Western Branch of Academy of Information Technologies in Education, Russia.
} 
traced in myths, legends, tales and other memory of culture of different Nations. For Western culture the major interest is tied with the New Testament, Tora and the Ancient Greek myths. These three most important areas of the old European pre-science period reflect different problems of ancient human mentality. So the New Testament gives us a brilliant picture of basic moral principles. The Tora reflects many historical facts. Greek myths and the later literature of the Greeks and Romans thoroughly acquaint the modern reader with basic ideas of Natural Philosophy and logic. Therefore, many books and articles are devoted to this problem. See for instance (Kirk 1971, Otto 1947). The Greek myths were never interested in human psychology. Most of their heroes were simple toys acting on the will of the gods. Gods themselves were usually personified natural phenomena. Therefore, the characters of myths possessed almost invariable behaviours.

The ancients of all countries were very observant. Through the description of any real fact they were able to get the main point of the character. As a result of multiple retellings, the basic trait of a hero was intensified and his (her) other traits were ignored. That is why, over time there were heroes with only one pronounced feature. One hero was the embodiment of physical strength, another one was mad, a third one was cunning, etc. Such were the heroes of all Nations. They and their achievements were very similar across all Nations. Therefore, over time, the heroes of neighbouring peoples are often merged into a single image. Along with this, some Nations had their own heroes and heroines, different from the others. Such a heroine was a heroine of the ancient Greek epic, Cassandra. In this way our ancestors identified traits that are interesting to recall in relation to our time. The analysis of her character is the main goal of this article.

\section{What Modern People Remember about Cassandra}

In the Greek cultural memory Cassandra appeares in many myths, plays and poems. Cassandra was probably first depicted briefly in the Illiad by Homer. In most cases, the average modern man does not remember all the events that are associated with her life. Yet, all of us remember that she was a prophet. Ancient mythology and history remember many prophets and predictors. Yet sometimes, the form of these forecasts was not defined. Therefore, their correct interpretation was very difficult. The behaviour of a hero, as vaguely predicted by a prophet, was the basis of many stories. The predictions given by Cassandra were usually quite certain. Unfortunately, almost all of them were terrible. She warned the residents of Troy of a fatal war with the Greeks. She foresaw the terrible death of many heroes, including her own murder. Only one of her numerous predictions was good. Her predictions were correct. Yet nobody believed her. So, the most amazing and unique feature of her personality was a contradiction between the truth of her predictions and the lack of faith people had in them. 
Cultural sources from ancient times provide an explanation of these features of her personality. They were the result of her love relationship with Apollo. These relationships as well as the other circumstances of Cassandra's life were described in detail in the literary heritage of the ancient Greeks and Romans (Parada 1995). Traditional education of the XIX century acquainted students with the principal issues of ancient literature. Yet, in modern times an average educated person is not so well informed in this area. Nevertheless, a number of some standard stereotypes associated with Cassandra is firmly stored in the background of a modern educated person. These ideas are the main interest of our task. Let us focus on them in more detail.

The first standard stereotype tied with Cassandra is that all bad or unwanted or unpleasant forecasting and statements are connected with her name. If someone predicts an unfavourable course of events people say: "It is a typical Cassandra prediction". This is perfectly described in a famous story: "The experiment of Professor Rouss" by the well known Czech writer Karel Capek (1994). For other instances, Professor Ferdinand Kirkk on July 17, 2015 took part in the discussion about the forests in Germany. He told "Sie werden von mir keine Kassandrarufe hören - You will hear from me no Cassandras call here" (Bremer 2015). The other stereotype is to connect different warnings about the tragic consequences of certain actions with Cassandra's name. The warning about the responsibility for undesirable activities, as well as disbelief in them, in the German language it is frequently called Kassandraruf. If desired, a large number of materials on this subject can be found in Wikipedia. The fate of Cassandra and her behaviours were studied by psychologists (Klein 1997, Shapira 1988). They used the term Cassandra metaphor. Thus, a symbolic image of Cassandra became a part of the modern life. It is barely associated with the subject of the myths about her. However, there are some reasons to return to this subject and its study from a slightly new point of view. This point is not psychological analysis of this mythological personality. Instead of this we focus on the question of the ability of person to convince others of the own correctness. First, it was done in our brief essay (Romanenko 2001). It was only a first attempt. The more accurate and reasonable analysis of this problem is mentioned below.

\section{The Connection between Specific Properties of Individual Persons}

It is well known that disparity between active and passive reflection of external actions is the main difference between animate and inanimate forms of matter. General processes of the interaction between any objects and its environment was described in (Romanenko and Nikitina 2014). One of the main conclusions of this work suggests that the complexity of reactions in living beings increases with increased complexity of the organisms. It is evident that the human reactions are the most complex known to us. Living being tries to predict the results of external influences (Feigenberg 2014). These predictions will determine their further actions. These actions define 
their behaviour. Unlike animals, human behaviour, in complex situations, is highly variable. Moreover, different individuals react differently to the same external influence in complex situations. This difference is important in the process of the evolutionary selection. The nature of human behaviour in complex circumstances depends on a set of specific properties. It should be noted that even the same properties can change their activity in different people.

The nature of predictions in social life is usually the most difficult and poorly explained. The most successful sages and prophets themselves often can't clearly justify the nature of their predictions. We can say these predictions are most likely intuitive. It is known that human senses partially changed in the process of evolution. For instance, people significantly reduced the role of pheromones as transmitters of information. In the article "Sages, Prophets, Leaders" (Romanenko and Nikitina 2012: 93-98) we assumed that some ancient Jewish prophets had residual sensitivity to small earth vibrations. This allowed them to feel the approach of earthquakes, which was very helpful. At the same time, they could not rationally explain the nature of their misgivings. Therefore, all explanations were sought in the mythical area. They were preserved in the cultural memory of ancient people. These stored recollections are extremely simplified as a result of numerous paraphrases and simplifications. They are the main subjects of ancient mythology. In the mentioned work (Romanenko and Nikitina 2012: 93-98), several examples of various types of residual sensitivity among different heroes of myths and epics are described. In those days people tried to explain such incomprehensible elements by the essence of the phenomenon.

Famous German Psychologist Ernst Kretschmer, in the preface to his well known book Körperbau und Charakter (Kretschmer 1921) wrote that in former times people often accurately remembered their observations and comparison, though they could not explain their causes. So they could associate appearance of a man with his main behaviours. As an example, Kretschmer notes that it was well known that short fat people are usually good natured and friendly. Opposite of this, sarcastic people are often thin and tall. The important fact of the analogous nature of ancient Greeks was reflected in Cassandra's behaviours. In the myths about her you can clearly see the empirical observation that the ability to foresee and the ability to convince of the correctness of this prediction are different features of an individual. The absence of a strong connection between these two features was reflected in her mythical image. It is quite strange that for a long time nobody paid attention to this - important and interesting human personality trait. Therefore, we call that The Cassandra effect which can be defined as the absence of a strong connection between the ability to detect and describe the problem and the ability to convince the others in these results (Romanenko 2001).

The essay (Romanenko 2001) only briefly describes the Cassandra effect and its importance for understanding difficult moments in the history of science. A more detailed analysis of this effect mentioned below. 


\section{The Sequence of Solving Scientific Problems and the Cassandra Effect}

All living beings interact with each other. It can be as competitive interaction or mutual aid. This idea was first pronounced by Peter Kropotkin in 1902. After this, his book was reprinted many times, its latest edition was in 2009. Stemming from this idea of innate altruism was at first proclaimed by V.P. Efroimson (Efremenko and Evseeva 2009). At modern time one knows that interactions between living beings are realized with three main types of flows: the flow of matter, the flow of energy and the flow of information. These flows can be input or output flows (Romanenko and Nikitina 2014). Different combinations of these main flows are possible. One also knows that the interactions between animated and non-animated material objects have a hierarchical structure.

Unlike other living beings, the major part of humans' interactions with each other is realized by communication. In the simplest form, communication can be represented as the following sequence of actions:

\section{Signal Processing $\rightarrow$ Signal Transmission $\rightarrow$ Signal Perception}

On the lower levels of interaction hierarchy there are no serious problems in this sequence. If, for example, somebody wants to eat, he (she) will almost always be understood. It is evident that when the interacting individuals do not have a common language they can use signs. With increased complexity of a situation, the above sequence starts losing the uniqueness. This can lead to incomplete or a false understanding of the signal or simply to the lack of its understanding. In other words, the reliability of communication links will be broken. This violation can be associated with any of the elements in the communication chain. It is not difficult to understand that at lower levels of communication contacts, people share basic information. At the same time, such simple signals as hunger, danger, sexual attraction etc. are always the most important for the survival of a living being. For this reason the communication in these hierarchical levels is the simplest in terms of a form and the most reliable as a sense of perception.

At lower levels of the communication hierarchy, the choice to be made by a living being is usually simple. For instance, a living being has to solve what is safer: to fight or run away. The cost of an error here is extremely high. As one moves to the higher levels of the communication hierarchy, the complexity of the situation increases. At the same time, the number of possible solutions to the problem gets bigger. Moreover, when the choice is made at the top hierarchical levels, errors are not immediately apparent. The cost of an error is also not as obvious as in the previous example.

The highest levels of people's communication hierarchy are tied with social life. In this field each participant sends and receives information flows from many other people. Therefore, the reaction of different people to the same signals can be very different. The behaviours of an individual are also formed by the action of many signals. In the process of perception, there is a horizontal 
information impact on other members of society. As a result, the behaviour of different individuals can be varied. Therefore, it is very often assumed that each signal will be perceived differently by some community members. Long ago in ancient times people tried to have their message heard. Even given a superficial look at the literary heritage of the Greeks, it is not difficult to see that most predictions given by various oracles, priests and prophets were deliberately fuzzy. In this situation the freedom of interpretation of the predictions was great. Therefore, in the case of most predictions, there were always people believing them. As a result, virtually at all times every utterance will always find its supporters in the public field. Yet, ancient Greeks first discovered that this empirical rule can be broken. They were probably the only people that clearly reflected this fact in their myths. It is their observation that was reflected in the image of Cassandra. Using modern terms is the essence of the phenomenon. As it was written above, we named the reflection of this fact The Cassandra effect (Romanenko 2001).

The Cassandra effect in fact notes the lack of an unambiguous connection between the signal and its perception. There may be a few reasons for this phenomenon. Their first group is associated with poor signal quality. The second one is tied to a perception system. And finally the third group of causes is associated with impaired communication channels between the person sending a signal and the person perceiving it. The sources of the latter group are quite obvious. Therefore, we should not dwell on them. Properties of the human personality often differ in their strength. As a result, the combination of the ability to form a clear signal and the ability to understand an incoming signal in different people varies widely. It is necessary to take into account that in real life the weakness of one of these abilities is often compensated by another force. In the image of Cassandra, our ancestors reflected a marginal case, which is not very common in life: the combination of the highest possible ability to foresee the course of events and the complete lack of ability to convince anyone of its correctness. Of course, at lower levels of communication contacts, this effect did not exist. If this were not so, Cassandra would not be able to be a member of the human community. In those days notions of hierarchy communication space had not been formed. Therefore, we can confidently assert that our ancestors never thought about this problem.

Summing up we can say that the ancient Greeks noted the remarkable feature of a man, which we have denoted The Cassandra effect. This effect appears in the social life of mankind. In other words, it is primarily important in politics and science. The usage of this observation (fact) in the field of innovations will be one of our goals.

\section{The Stages on Innovation and Scientific Development and the Cassandra Effect}

The ways of producing new knowledge, new technical and processing ideas, new services and political transformations are complex and long term. In 
most cases serious changes in human knowledge both in the technical and political environment is a result of activities of many participants (agents). This situation is not accidental. Its origin is attributed to the heterogeneity of the problems to be solved. As an example let us consider the sequence of actions one needs for the solution of any scientific problem. It is not difficult to understand that the first stage on this way is to clearly identify a new problem. One can face various situations there. An explanation of unclear data may be needed. In another case, it may be necessary to prove some theorems. One can meet some others to compare various data, the creation of desirable device or creation of a new process. One can face obscure problems. In all such cases at first, one should find a contradiction or define a correct question. As the result a new problem is created (Moore 2014). Let us call this stage as the definition of the problem.

The history of sciences and techniques gives us many examples of when a problem is identified and formulated, but its solution is unknown. It is typical that we call this stage the definition of the problem. Various lists of such detected but not solved problems are well known in scientific practice. See for instance (Abe and Tanaka 2001). One has to understand that the reasons that a problem is not solved may be very different.

After the problem is strictly defined, another stage comes, which we call the solution of the problem. Sometimes the stage of the solution begins immediately after its definition. Moreover, there are well known situations when the solutions started even when the definition was not fully understood. For example, the term globalization was introduced to science by Roland Robertson in 1992 only (Robertson 1992). At the same time, such globalization phenomena as the spread of alphabetical writing or acclimatization in Europe, cherries, potatoes and many other agricultural cultures are known and described much earlier. However, in the case of very complex and difficult problems, the time interval between the definition of the problem and its successful solution may be in many years. For many pure theoretical problems these two stages may be sufficient. However, in many cases, one needs special efforts to understand a solved problem. In other words, a specific stage of the implementation of the new results into a General scientific paradigm is required. We call this third stage the implementation of the problem solution. So, the complete sequence of actions which create new knowledge consists from three main successive stages:

\section{Definition of the Problem $\rightarrow$ Solution of the Problem $\rightarrow$ Implementation of the Problem Solution}

The same stages are more evident in cases of technical, production or services innovations (Moore 2014, Rogers 2003, Sismondo 2010). Each of these stages requires different abilities of the innovator. As we have already mentioned, the combinations of various human properties needed for successful work at all three stages of creating new knowledge, are various. The desired combination of human properties, required for the successful 
implementation of all three creative stages, in one person is rare. Therefore, frequently an individual who is able to find a solution for one of these stages is unable to find answers necessary to find a solution for the other ones. This condition, i.e. the ability to find a solution to one stage and the lack of data for the other stages, was recognizes by the ancient Greeks. It was reflected in a symbolic form in the myths about Cassandra. In other words: what we call the Cassandra effect actually reflects the characteristics connected with the range of abilities of an individual. No doubt, there are people who successfully manage to find solutions at two and sometimes at all three stages. Such cases are certainly rare. People who have such a set of properties are often considered geniuses. Yet, in most cases a person has a strong creative force which enables him (her) to cope with one of the three main parts of the creative triad. Sometimes, such a person can solve the other parts of the creative triad with difficulties. In reality, the most common case is when the execution of these parts is associated with different people.

From the formal point of view, one can say, that because of the Cassandra effect, the full analysis of a complex problem is fulfilled by several people. This can be considered a matter of principle. Misunderstanding of this circumstance often leads to errors in assessment of the role of different participants in achieving new results. If one takes into account that the development of many new ideas is tied with the set of successive refinements it will be clear, how many people are usually involved into the creative process. The efforts of many of them are often not very noticeable because they lack the ability to convince others of the correctness of their ideas. Let us give a simple example. The famous German scientist Johann Christian Poggendorff (17961877 ) is well remembered for the organization of the scientific journal Annalen der Physic and Chemie and his work in Handwörterbuchden reinen und angewandten Chemie. He was the one who, until 1860, made the decisions on what works would be published in the first of these journals. The success and usefulness of these projects is highly appreciated in the memory of the scientific community (Salie 1963).

Among the materials, which were rejected by Poggendorff, there were articles by Gregor Johann Mendel (genetics) and Johann Philip Reis (invention of the telephone). In principle, the rejection of Mendels manuscript can be explained by the fact that Poggendorff was a physicist. However, this explanation in relation to two Reis' manuscripts is not valid. Poggendorff was familiar with the area of Reis' professional interests (Coe 2006). It is well known that Mendel sent 400 copies of his preliminary article to approximately 400 addresses. He did not receive any responses. We are not going to describe the history of these scientific discoveries. We only want to draw attention to the fact that such stories are widespread. Even a superficial analysis shows that the cause of this is that the authors did not have the necessary skills to attract attention to their results. This is precisely the circumstance noted by the ancient Greeks in the myth of Cassandra. 
In the history of the creation of new techniques and new processes, this effect is observed even more clearly. In this area the sequence of creativity actions is usually represented as:

\section{Invention $\rightarrow$ Innovation $\rightarrow$ Distribution}

The process of the implementation of a new product or a new service leads to finding a consumer of the products or services and ensuring demand for them. In this case the last stage (distribution of products) requires completely new personal abilities connected with advertising, marketing and managing.

Let us explain this situation with the help of a historical example related to the history of sewing machines. A brief history of the invention of sewing machines is described in (Forsdyke 2015). This history includes many inventors. The last one was very successful, Elias Hawk. Yet, the very important role in the process of his machine spreading across the whole world was played by Isaak Singer. His contribution to the technical improvement of the Hawk's sewing machine was little. Yet, Singer made the decisive step for its promotion at the market. At that time the price of a new sewing machine was about $\$ 100$. It was a lot of money then. Singer lived in NYC and worked in a sewing machines repair shop. He knew how many tailors worked at that time in the city. Yet, they did not get enough money to buy this necessary tool. Singer proposed to take only $\$ 10$ from a tailor and to give him the right to use the machine and pay its cost gradually. This idea created an extensive market and made both Singer and Hawk multimillionaires.

We can add to the above that Singer cleverly formulated the sense of his invention. He proclaimed that the main part of his sewing machine was a needle with a hole near its sharp end. In any sewing machine the second end of the needle is fixed in the holder. It is clear that it is impossible to fix in a holder the needle with a hole on its blunt end. That is why all sewing machines must have a hole in a sharp and only. Another type of the needle in sewing machines of any design cannot be used. This claim secured Singer's success in the struggle with competitive technical ideas. This wording by Singer was so excellent that it came in as an illustrative example in many textbooks. The formulation of the essence of the main part of the invention in combination with an effective method of product sales ensured Singer's great success in the market. It is not difficult to understand that Singer's personal traits are not directly related to engineering activities. Singer himself had engineering skills. He created a number of improvements to Hawk's sewing machine and he received 22 patents in total. However, his technical contribution to the improvement of the machine design was not significant.

At the end of our brief analysis we can say that the crucial point in the successful marketing of sewing machines was a specific trait of Singer's personality. Almost all of Singer's predecessors did not possess these properties. They had strong engineering and design skills, yet they could not identify and solve valid management problems. So, this story is a good illustration of the fact that people with different sets of abilities are needed in 
order to solve problems to achieve a successful innovation. One can only wonder how long our ancestors could understand this. Therefore, the expression "Cassandra effect" is a deserved tribute to the memory of their observation.

\section{Brief Theoretical Explanation}

The main question that arises when one talks about the Cassandra effect is tied to the randomness of this phenomenon. This is, practically no one has the full set of the properties required for the realization of the whole sequence. Different people have these properties activated at different levels. To understand the problem let us analyse a simple example from the technical area. The basic options of a cell phone are to make calls and send text messages. Gradually these options were complimented with photographing, recording information, searching for news on the Internet, etc. All this, step by step, turned a phone into a multipurpose device, i.e. a gadget. Naturally, this gadget is not as good as camera for taking shots. However, for ordinary images the properties of this gadget are quite reasonable. It is for this reason that modern technical lines frequently combine multipurpose and very specific devices.

This situation is typical in more than just the technical world. In human society the situation faced by people diverse. That is why for the effective functioning of society, people with different abilities and nervous system types are needed. Despite many attempts, it was not a universal organism that was created as a result of the evolution of life on Earth. The interaction of organisms with different properties was used instead (Kropotkin 2009). This creates diverse opportunities, and at the same time it speeds up the process of evolution. In social life, the diversity of human actions is provided thanks to the presence of persons with different psychological, creative and mental properties. In principle, all people possess a similar set of mental and psychological properties. Yet, these properties are spread between various individuals in different proportions. Therefore, in terms of these properties, all people are divided into several groups. People belonging to these groups vary in their preferences, the possibilities of communication and types of reaction to external stimuli (Kretschmer 1921, Jung 1976, Blunter and Hochandel 2009). There are 16 groups of human mental and psychological behaviours (Blunter and Hochandel 2009). These types of behaviours are studied in details by the special science called socionics (Fisher et al. 2005).

The situation in the field of innovation work is probably more complex. However, there are no doubts that various types of personal behaviours are necessary to achieve successful results in the provision of new ideas. Moreover, it is obvious that in order to have each stage of creative actions sequence be successful, the participants should have different strengths of the mental properties in their personalities. This explains why each serious innovation is usually tied with several persons. In our opinion, these brief 
discussions support the importance of the Cassandra effect discovered by our ancestors.

The Cassandra effect explains why it is so difficult to identify the authors of technical innovations and scientific discoveries. Many individuals who first discovered a new problem did not achieve success. This often resulted in personal tragedies (Romanenko 2001). For example, due to miscommunication the famous physicist Ludwig Boltzmann committed suicide. For the same reason, one of the authors of the energy conservation law, Julius Robert von Mayer attempted suicide. The historical memory keeps many stories of this kind, evidence of disputes about priority and other materials which reflects the difficulties in finding the real author. There are several books which gathered such stories, see for instance (Orlov 1980). The upshot of this problem is that the difficulties of the implementation of new ideas into society are not accidental. Being an innovator requires a lot of qualities that are difficult to find in one person. Therefore, the study of the history of new discoveries and the biographies of their authors should be taken into account in modern university curricula. The mention of the Cassandra effect can be a starting point in teaching this.

\section{Opportunity of Familiarization with New Ideas}

Each new idea goes beyond the accepted community paradigm. Partial adjustment of scientific views is often required for its adoption. The understanding of novelty depends on how much its content differs from a standard point of view. Some novelties do not affect the paradigm much. That is why they are easily accepted. On the contrary, cardinal changes are often rejected because of misunderstanding. It is hardly possible to access the optimal degree of a novelty in advance. As a result, the success of its implementation often depends on the talent of its author. In many cases, a promising idea is born long before there are real opportunities for its implementation. Under such circumstances, a new idea may be lost. However, some authors found an opportunity to convey their thoughts to the future times. It was reflected in myths and tales in ancient times and now it is reflected in science fiction.

If one tries to systemize different novels in the area of science fiction he (she) immediately can divide their authors into several groups (Romanenko and Nikitina 2015). The first group of authors creates a fantasy only for the sake of having an entertaining story. The second group is interested in familiarization of a reader with the latest achievements in science and technology, with historical events, or new places. A typical representative of this group of authors can be the French writer Jules Gabriel Verne. Finally, the third group of authors explores new situations. Authors of this group use several types of plots. This may be the behaviour of an ordinary person in unexpected circumstances. In opposite, many authors prefer to create heroes with extraordinary behaviours. Sir Thomas More wrote in 1516 the famous Utopia 
which marked the beginning of a huge number of works of social fiction. There are many books devoted to their study, for instance (Davis 1983). However, from the standpoint of nominating fundamentally new scientific ideas, one can distinguish a specific group of authors. Some of them are renowned scientists, and they acquaint the readers with the hypotheses in the field of knowledge of their expertise. One of such authors was the renowned astronomer and cosmologist Sir Fred Hoyle. He wrote some science fiction stories and novels. The most famous of them was The Black Cloud (Hoyle 2010), first published in 1957. This novel generated many discussions of the basic idea.

Among the authors of this group there are a few people who use science fiction for promotion of new ideas and as a platform of futurological forecasts. The most famous of them is the Polish writer Stanislaw Lem. We discussed in detail his researches and predictions in (Romanenko and Nikitina 2015). Let us give only one example of his foresights. In 1973 the Polish publishing house Wydawnictwa Czytelnik published Lem's collection of short stories named Wielkość urojona (The Imaginary of Magnitude). This was a collection of prefaces to newer written scientific stories. Yet in fact, it was a set of new scientific ideas. One of these pseudo prefaces was called Reginald Gulliver. Eruntyka. In this story Lem talks about a set of experiments on the bacterial colonies made by the fictional scientist Reginald Gulliver. These bacterial communities could change their shape on a nutrium medium under external influence. At that time this idea looked like a pure fantasy. Yet, in (Be'er et al. 2009) one can read a series of articles where the analogous effect was studied. In one of the first articles in this area (Miller and Busler 2001) this effect was called Quorum sensing. So, it is clear that Stanislaw Lem was able to correctly predict future discoveries.

Lem's prediction mentioned above was not the only one. It is hardly possible to write a list with numerous predictions given by him. They cover many fields of human knowledge. Some of them have already been proved true. Some other gave a start to serious investigations. One of the studied problems, which were born after Lem's writing, is the idea sometimes called the Super-brain (Lugovskoy 2005). Stanislaw Lem is not alone in this regard. It is possible to say that several people with good backgrounds, who understand that their ideas are born too early, use the area of science fiction as the place where it is possible to store their ideas until better times. One can say that it is a branch of futurology. Authors who are active in this field possess a rare combination of personal behaviours. These behaviours are not only a gift for scientific prediction. For effective combination it is also important to have a literary talent, such as the ability to build an exciting story. According to the Cassandra effect it is possible to say that such a combination is not widespread.

\section{Conclusions}

The diversity of human mental properties causes variability of human reactions and their possible actions in different situations. In most cases this is 
closely tied with the different activation of a certain common set of human properties. New ideas necessary for social and technical evolution require from their authors various sets of properties. To fulfil all requirements of an innovation process, its participants have to possess a set of very different mental properties. The experience of many ages shows that their necessary combination in a single person is practically impossible. For various stages of the creative process its participants should possess different behaviours. Therefore, a number of authors are required for a creative process. This fact was first detected by the Ancient Greeks. They reflected this observation in the set of myths and legends devoted to Cassandra. The explanation of this observation was born only in modern time. Several well known stories reinforce this explanation. An additional output from studying the Cassanda effect is an indication of usefulness of the study of the Ancient literature sources which can help understand many practical observations.

\section{References}

Abe JM, Tanaka S (Eds) (2001) Unsolved Problems on Mathematics for the 21st Century: A Tribute to Kiyoshi Iséki's $80^{\text {th }}$ Birthday Amsterdam, Berlin, Oxford, Tokyo, Washington DC: IOS Press.

Be'er A, Zhang HP, Florin E-L, Payene SM, Ben-Jacob E, Swinney HL (2009) Deadly competition between sibling bacterial colonies. Proceedings of the National Academy of Science of the United States of America 106 (2): 428-433.

Blunter R, Hochandel E. (2009) Two qubits for C.G. Jung's theory of personality Retrieved from http://bit.ly/2a1HODV. [Accessed 22 February 2016].

Bremer S (2015) Keine Kassandrarufen [No Cassandras]. Retrieved from http://bit.ly/29gCCXw. [Accessed 14 February 2016].

Capek K (1994) The Experiment of Professor Rouss. In Tales from Two Pockets. North Haven, CN: Catbird Press.

Coe L (2006) The Telephone and its Several Inventors $2^{\text {nd }}$ ed. Jefferson V.C. McFarland \& Co Inc.

Davis JC (1983) Utopia and the ideal society. A Study of English Utopia Writing (1516-1700). London, NY: Cambridhe University press.

Efremenko D, Evsseeva Y (2009) Studies of Altruism and Solidarity in Russian Social Science. Altruism \& Social Solidarity 1(2): 22-23.

Feigenberg JM (2014) Memory, probabilistic prognosis, and presetting for action. Retrieved from http://bit.ly/2afol8B. [Accessed 21 April 2015].

Fisher K, Florian M, Malsch T (2005) Socionics: Scalability of Complex Social Systems. Berlin, Heidelberg, NY: Springer.

Forsdyke G (2015) A brief history of sewing machine. Retrieved from http://bit.ly/ 1FRBsOT. [Accessed 22 February 2016].

Hoyle F (2010) The Black Cloud. London: Penguin Classics.

Jung CG (1976) Psychological Types, Vol. 6, 2nd ed. Princeton NJ: Princeton University Press.

Kirk GS (1971) Myth. Its meaning and functions in ancient and other cultures. Cambridge/ Berkley/ Los Angeles: Cambridge University Press/ University of California Press. 
Klein M (1997) Envy and gratitude and other works 1946-1963. Conteporary Classics. London: Vintage.

Kretschmer E (1921) Körperbau und Charakter. untersuchungen zum konstitutionsproblem und zur lehre von den temperamenten. [Physique and character: the studies of body and the study of temperament] Berlin: Springer.

Kropotkin P (2009) Mutual aid: a factor of evolution. London: Freedom Press.

Lugovskoy VM (2005) Supermozg polulyatsii i perspektivy chelovechestva [Superbrain of population and humankind perspectives]. Jerusalem: Health and Healing Ltd.

Miller MB, Busler BL (2001) Quorum sensing in bacteria. Annual Review of Microbiolgy 55: 165-199.

Moor AD (2014) Inventive Problem Solving (TRIZ) Principles. American Journal of Applied Sciences 7(6): 852-858.

Orlov VJ (1980) Traktat o vdochnovene, rozhdayushchem velikie izobreteniya [A treatise on the inspiration that gives birth to great inventions] $2^{\text {nd }}$ ed. M:. Znanie.

Otto WF (1947) Die götter des Griechenlahds: Das Bild des Gottlichen im Spiegel des griechischen Geistes [The Gods of Greeks: The image of the Divine in the mirror of the Greek spirit]. Vol 3. Frankfurt.

Parada C (1995) Genealogical guide to Greek mythology. Jonsered: Paul Astroms.

Robertson R (1992) Globalization: Social Theory and Global Culture. London: Sage.

Rogers EM (2003) Diffusion of innovations $5^{\text {th }}$ ed. NY: Simon \& Schuster, Inc.

Romanenko VN (2001) Cassandra effect. In Ocherki I Vospominaniya [Essays and Memories], 75-78. Saint-Petersburg.

RomanenkoVN, Nikitina G (2012) Mudretsy, Proroki, Vozhdi [Sages, Prophets, Leaders]. In Nauchnye I Pedagogocheskie Vyzovy Nachala XXI Veka: Predvaritelmnyi Analiz [Scientific and Pedagogical Challenges of the early XXI Century: Preliminary Analysis], 93-108. Saarbrücken: Lap Lambert Academic Publishing GmbH \& Co:

Romanenko VN, Nikitina G (2014) How the physical world impacts different objects. Studies in Sociology of Science 5(3): 40-43.

Romanenko VN, Nikitina G (2015) Predtechi [The Baptists]. In Collection of Essays, 51-70. Saint-Petrsburg: Norma.

Salie H (1963) Ein Standardwerk zur Geschichte der Naturwissenschaften: Hundert Jahre 'Poggendorf' [The overview of the history of Science: One hundreed years of Pofggendorf's]. Forschungen und Forschritte 37: 202-205.

Schapira L (1988) The Cassandra Complex: Living With Disbelief /A Modern Perspective on Hysteria. Toronto, ON: Inner City Books.

Sismondo S (2010) An Introduction to Science and Technology Studies $2^{\text {nd }}$ ed. Chichester, West Sussex, UK, Madlen. MA: Wiley-Blackwell.

Vygotsky LS (1978) Mind in Society. Cambridge, MA: Harvard University Press.

Vygotsky LS (1986) Thought and Language. Cambridge, MA: MIT Press. 